\title{
Hemoglobin Trait
}

National Cancer Institute

\section{Source}

National Cancer Institute. Hemoglobin Trait. NCI Thesaurus. Code C95534.

A condition in which a person is heterozygous for a globin gene, with a one normal allele and one defective allele. 